\title{
A comparative study of p53 immunoexpression in parathyroid hyperplasias secondary to uremia, primary hyperplasias, adenomas and carcinomas
}

\author{
Marcia J Kayath, Luciana C Martin, José Gilberto H Vieira, Leonor M Roman ${ }^{1}$ and Vânia Nosé-Alberti ${ }^{1}$ \\ Division of Endocrinology and ${ }^{1}$ Department of Pathology, Federal University of São Paulo, Escola Paulista de Medicina, Brazil \\ (Correspondence should be addressed to M J Kayath, Division of Endocrinology, Escola Paulista de Medicina, Federal University of São Paulo, \\ Caixa Postal 20266, 04034-970, São Paulo - SP, Brazil)
}

\begin{abstract}
Objective: To investigate immunoexpression of p53 in parathyroid tumors and hyperplasias and correlate it with the histopathological diagnosis and severity of hyperparathyroidism.

Design: A total of 102 parathyroid tissues from archival paraffin-embedded specimens or obtained at surgery between 1988 and 1997 from 65 consecutive individuals with hyperparathyroidism were studied.

Methods: p53 immunoexpression, gland mass, preoperative serum calcium and intact parathyroid hormone (PTH) were analyzed; 14 normal parathyroid glands were used as controls.

Results: The histopathological findings were: adenomas $(n=28)$, primary hyperplasias $(n=12)$, secondary nodular and diffuse hyperplasias (patients with uremia, $n=57$ ), carcinomas $(n=4)$ and carcinomatous metastatic tissue $(n=1)$. Nuclear p 53 was detected in $36 \%$ of the adenomas, $42 \%$ of the primary hyperplastic glands, $72 \%$ of the diffuse hyperplasias, $44 \%$ of nodular hyperplasias and $40 \%$ of the carcinomatous tissues, and was absent from normal glands. p53 expression was significantly more frequent in diffuse hyperplasias than in adenomas $(P=0 \cdot 037)$. Serum ionized calcium tended to be higher in p53-positive glands in all histopathological groups; however, the difference was only significant in nodular hyperplasias $(P=0 \cdot 018)$. The same trend was observed for serum intact PTH levels of adenomas and nodular hyperplastic glands. Gland mass was not significantly different according to $\mathrm{p} 53$ staining.

Conclusions: p53 immunoexpression was not useful in differentiating between the histopathological parathyroid subgroups. p53 immunodetection was particularly frequent in secondary hyperplastic glands of uremic patients. Our study suggests that $\mathrm{p} 53$, whether wild-type or mutant, is regulated in parathyroid tumors and hyperplasias. Changes in wild-type p53 may be part of a cellular response to a hyperproliferative condition.
\end{abstract}

European Journal of Endocrinology 139 78-83

\section{Introduction}

Hyperparathyroidism is a common disorder characterized by hypercalcemia due to increased parathyroid hormone (PTH) secretion. In most cases, a single adenomatous gland is responsible for the metabolic derangement, but a significant fraction of cases may have hyperplasia and less commonly carcinoma. In uremic patients with refractory hyperparathyroidism, the usual finding is hyperplasia of all parathyroid glands.

Most parathyroid adenomas and hyperplasias so far studied have been shown to be monoclonal neoplasms (1-4). Deregulation of genes such as PRAD1/cyclinD1 and retinoblastoma protein $(\mathrm{pRB})$ have been implicated in the pathogenesis of these tumors, the latter being especially involved in the genesis of parathyroid carcinomas (5-7). p53, a tumor suppressor gene, encodes a $53 \mathrm{kDa}$ nuclear phosphoprotein that is important in regulating the cell cycle, by arresting the cycle at the G1-S interphase (8). p53 expression has been shown in a variety of malignancies, and in many tumours has been correlated with prognosis $(9,10)$. In parathyroid tumors, abnormal expression or mutations of p53 have been described by some in a fraction of adenomas (11-13) and by others only in carcinomas (14). Other authors have failed to find any p53 mutations in parathyroid tumors (15). Expression of p53 protein has never been specifically evaluated and described in secondary hyperplasias due to uremia.

In this study, we have evaluated the expression of immunoreactive $\mathrm{p} 53$ in a large series of parathyroid tumors and hyperplasias, including secondary hyperplastic glands from uremic patients. Our aim was to determine the expression of this protein in the different 
Table 1 Distribution of parathyroid tumors and hyperplasias by number of patients and number of tissues.

\begin{tabular}{lcc}
\hline Histopathological diagnosis & No. of patients & No. of tissues \\
\hline Adenoma & 28 & 28 \\
Primary hyperplasia & 4 & 10 \\
$\quad$ Sporadic & 1 & 2 \\
MEN 1 & & \\
Secondary hyperplasia & 6 & 18 \\
$\quad$ Diffuse & 18 & 39 \\
$\quad$ Nodular & 4 & $5^{\star}$ \\
Carcinoma & 65 & 102 \\
Total & 12 & 14 \\
Normal tissue & & \\
\hline
\end{tabular}

* Four glands and one cervical metastasis.

MEN 1, multiple endocrine neoplasia type 1.

histopathological parathyroid lesions. We also evaluated whether $\mathrm{p} 53$ expression correlates with gland mass and degree of hyperparathyroidism.

\section{Materials and methods}

A total of 102 parathyroid tissues were obtained at surgery or from archival paraffin-embedded specimens. The study group consisted of 65 consecutive individuals (20 males and 45 females) aged 10-75 years (median 49 years) operated on between 1988 and 1997. We also studied 14 normal parathyroids obtained during surgery of the thyroid or parathyroid. Sections $(5 \mu \mathrm{m})$ were stained with hematoxylin and eosin. Patients were classified as having adenoma, primary hyperplasia, secondary hyperplasia (uremic patients) or carcinoma according to previously established histological criteria $(16,17)$. The glands with secondary hyperplasia were further categorized as diffuse or nodular depending on the presence of nodular cell arrangements. A summary of the histopathological diagnosis is given in Table 1. Gland mass was estimated using the dimensions recorded and the following formula for the mass of an ellipsoid: (4/ $\left.3 \times r_{1} \times r_{2} \times r_{3}\right) \times D$, where $D$ is a water density of $1 \mathrm{~g} /$ $\mathrm{cm}^{3}$ and $r_{1}, r_{2}$ and $r_{3}$ are the orthogonal radii (18).

Ionized calcium levels were determined by an ionspecific electrode technique (normal range 1.14$1.29 \mathrm{mmol} / \mathrm{l}$ ), and serum intact PTH levels by a two-site immunofluorimetric assay (normal range $10-65 \mathrm{pg} / \mathrm{ml}$ ) (19).

Immunohistochemistry was performed on formalinfixed paraffin-embedded sections using the streptavidin-biotin-peroxidase-conjugated detection system as described (20). A monoclonal antibody that recognizes the mutant and the wild-type forms of p53 was used (DO-7; Dako Corp, Santa Barbara, CA, USA; dilution 1:100). A colonic adenocarcinoma known to unequivocally express p53 was used as a positive control. Incubation with preimmune serum instead of the primary antibody was used as a negative control.
Table 2 Nuclear p53 immunoreactivity in the different histopathological diagnoses.

\begin{tabular}{lc}
\hline Histopathological diagnosis & $\begin{array}{c}\text { Number } \\
\text { (\%) of p53-positive glands }\end{array}$ \\
\hline Adenoma $(n=28)$ & $10(36)$ \\
Primary hyperplasia $(n=12)$ & $5(42)$ \\
Secondary hyperplasia & \\
Diffuse $(n=18)$ & $13(72)^{\star}$ \\
Nodular $(n=39)$ & $17(44)$ \\
Carcinoma $(n=5)$ & $2(40) \dagger$ \\
\hline
\end{tabular}

${ }^{*}$ Diffuse hyperplasia vs adenoma, $P=0.037$; diffuse hyperplasia vs nodular hyperplasia, $P=0.08$ (Mann-Whitney test). Prevalence of nuclear p53 not significantly different among other groups. †Cervical metastasis and primary tumor of the same patient.

Other negative controls (tissues known not to express p53) such as lymphatic nodes or normal bowel epithelium were also tested and reacted appropriately. All controls were taken through the full immunostaining procedure. p53 staining was considered positive if cells showed nuclear p53 protein staining. The p53 index was calculated by evaluating the nuclear staining of 10 consecutive fields. Each field consisted of a mean of 80 nuclei, and the index was expressed as the number of positively stained nuclei divided by the total number of cells analyzed. Immunohistochemical detection of p53 protein was correlated with tumor histology, gland mass, preoperative PTH and calcium levels.

\section{Statistical analysis}

p53 index and other parameters of the different histopathological groups were compared using the Mann-Whitney test, and a $P<0.05$ was considered significant.

\section{Results}

\section{Immunohistological findings}

Nuclear p53 immunoreactivity was detected in all histopathological diagnoses (Table 2). Representative examples of p53 immunoreactivity in diffuse and nodular parathyroid hyperplasia are shown in Fig. 1. p53 expression was more frequently found in diffuse hyperplasias, but it was significantly higher only when compared with adenomas $(P=0.037)$. p53 was detected in only one of the four patients with parathyroid carcinoma and this patient was also the only one with tumoral metastasis. We analyzed the primary tissue and cervical metastasis of this patient, and the p53 index was higher in the metastatic site $(50 \%$ positive nuclei in the metastatic site vs $10 \%$ positive nuclei in the primary tissue). Mean percentage positive nuclear p53 staining was similar among the other histopathological groups (p53 index: adenomas, 40 $25 \%$ (range 10-80\%);

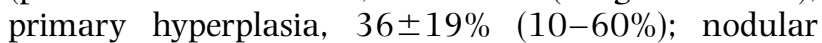



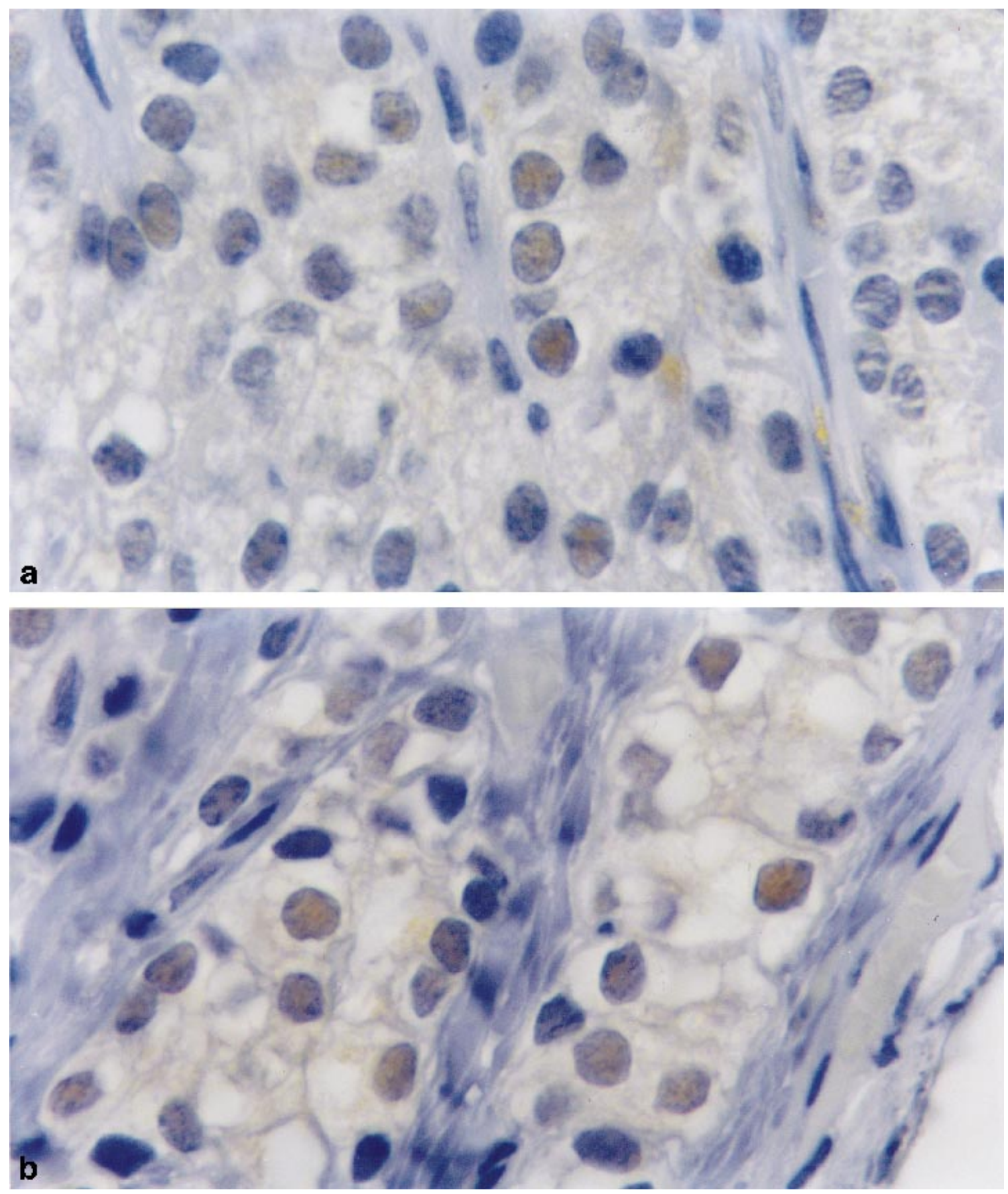

Figure 1 Diffuse parathyroid hyperplasia (a) and nodular type hyperplasia (b) with nuclear p53 immunodetection in hyperplastic cells and absence of $\mathrm{p} 53$ expression in vascular endothelial cells (immunoperoxidase for $\mathrm{p} 53 ; \times 1000$ ).

hyperplasia, $42 \pm 23 \%$ (10-80\%); diffuse hyperplasia, $45 \pm 23 \%(10-80 \%))$. No normal parathyroid glands exhibited p53 expression (not shown).

The gland masses of adenomas and diffuse and nodular hyperplasias were not significantly different with respect to p53 immunoexpression, although there was a trend for a higher mass in p53-positive adenomas and nodular hyperplastic glands (Fig. 2). Masses for all the primary hyperplastic glands were not available. 
A

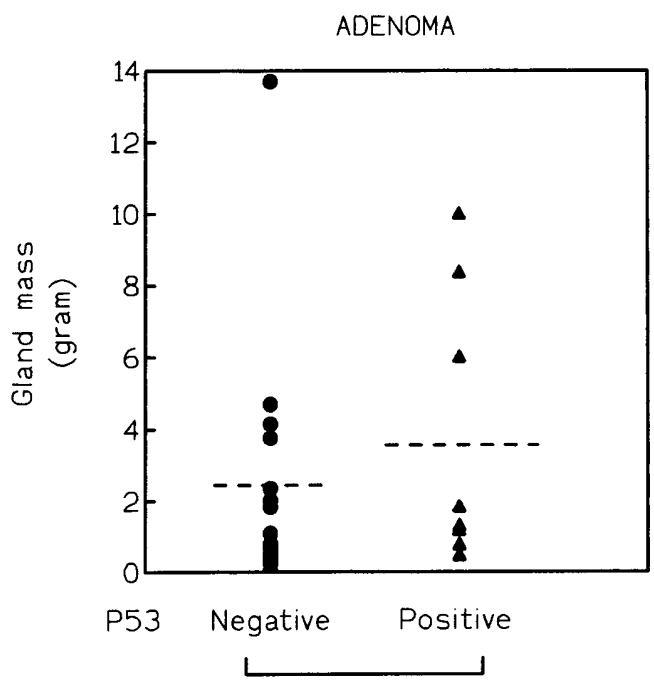

NS
$\mathrm{B}$

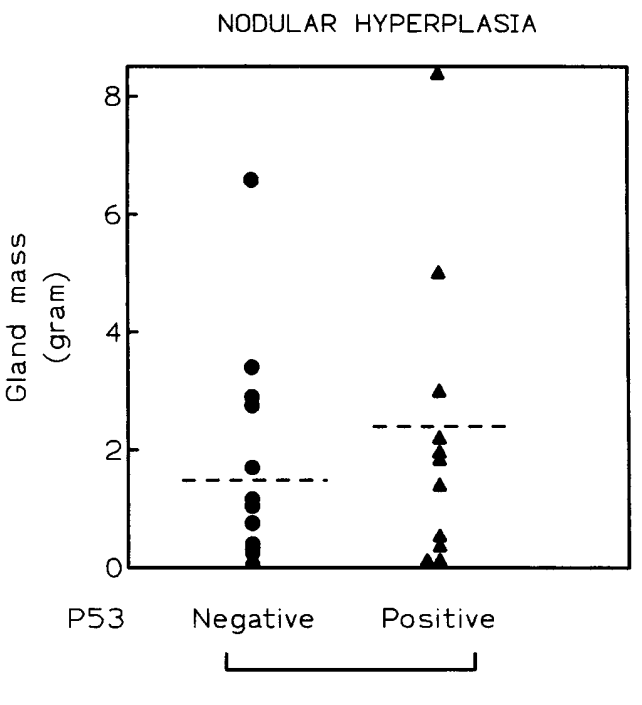

NS

Figure 2 Individual and mean (dashed lines) gland mass of p53-negative $(\bullet)$ and p53-positive ( $(\mathbf{\Lambda})$ adenomas (A) and nodular type hyperplasias (B). NS, Not significant.

\section{Biochemical findings}

Preoperative intact PTH and ionized calcium levels in the different histopathological groups according to the presence of p53 immunoexpression are presented in Table 3. Although PTH and ionized calcium levels were usually higher in patients with p53-positive parathyroid glands, only the ionized calcium in nodular hyperplastic glands was significantly higher than in p53-negative nodular hyperplastic glands $(P=0.018)$.

\section{Discussion}

We studied a large group of parathyroid tumors and hyperplasias for evidence of p53 abnormalities using protein expression. p53 immunostaining was found in all histopathological groups and was not detected in normal glands. Approximately $36 \%$ of the adenomas and $42 \%$ of the primary hyperplastic glands were p53-positive.
This prevalence was higher than in other studies, in which p53 immunostaining was found in $12-20 \%$ of adenomas (11-13) and $22 \%$ of hyperplasias (12). In uremic patients, $43 \%$ of nodular and $72 \%$ of diffuse hyperplastic glands were positive.

p53 is a protein with a short half-life and cannot usually be detected by immunohistochemistry (10). Most p53 gene mutations are believed to induce stability of the protein and a longer half-life, allowing p53 detection by immunohistochemistry (10). However, immunodetection of $\mathrm{p} 53$ sometimes does not correlate with DNA mutations $(21,22)$, indicating that there are alternative mechanisms whereby p53 can be stabilized (23-25).

p53 protein is a negative regulator of cell growth (8$10,26,27)$. The accumulation of nuclear p53 found in hyperplastic parathyroid glands could be a physiological and reactive response of native p53 in actively proliferating cells (28-31). The presence of p53 protein

Table 3 Preoperative mean serum intact PTH and ionized calcium levels in adenomas and hyperplastic glands according to negative or positive p53 immunoexpression. Values are mean \pm S.D.

\begin{tabular}{llllll}
\hline & \multicolumn{2}{c}{ Ionized calcium $(\mathrm{mmol} / \mathrm{l})$} & & \multicolumn{2}{c}{ Intact PTH $(\mathrm{pg} / \mathrm{ml})$} \\
\cline { 2 - 3 } & Negative & Positive & & Negative & Positive \\
\hline Adenoma & $1.53 \pm 0.18$ & $1.63 \pm 0.2$ & & $388 \pm 481$ & $664 \pm 635$ \\
Primary hyperplasia & $1.44 \pm 0.15$ & $1.61 \pm 0.2$ & & NA & NA \\
Diffuse hyperplasia & $1.2 \pm 0.1$ & $1.46 \pm 0.2$ & & NA & NA \\
Nodular hyperplasia & $1.27 \pm 0.1$ & $1.53 \pm 0.2^{*}$ & & $988 \pm 686$ & $1256 \pm 725$ \\
\hline
\end{tabular}

${ }^{*} P=0.018$ (Mann-Whitney test).

NA, Not available for all patients. 
has previously been described in $22 \%$ of primary parathyroid hyperplasias (12). Immunoexpression of p53 has also been detected in other hyperproliferative and reactive conditions, such as keloid, pyogenic granuloma, fasciitis and proliferative myositis, and pseudoepitheliomatous hyperplasia $(28,29)$. p53 positivity has also been demonstrated in normal and hyperplastic tissues in proximity to squamous cell carcinomas and in reactive fibroblasts $(31,32)$.

On the other hand, the immunodetection of p53 could be due to DNA mutations, and this would suggest that p53 abnormalities may be involved in the early pathogenesis of parathyroid hyperplasias in chronic renal failure. Glands with diffuse hyperplasia are usually smaller than nodular type ones and are usually present at an earlier stage of chronic renal failure $(16,17)$.

p53 gene abnormalities in parathyroid tumors have been previously described in only a minority of adenomas (11) and in some parathyroid carcinomas (11-13), although some authors have been unable to find any p53 point mutations in parathyroid adenomas or carcinomas (15). Lesions in one p53 allele may play a role in the pathogenesis of a small subset of parathyroid adenomas, but such mutations, together with loss of the wild-type p53 allele, appear to be restricted to parathyroid carcinomas (11). p53 allelic loss also seems to be quite specific for parathyroid carcinomas (11). Vargas et al. (14) found p53 immunoexpression only in parathyroid carcinomas and not in adenomas. However, Subramaniam et al. (12) observed nuclear p53 immunoreactivity in two of three carcinomas, $12 \%$ of the adenomas $(n=25)$ and $22 \%$ of the hyperplasias, mainly from patients with multiple endocrine neoplasia type 1 syndrome $(n=58)$.

The weight of p53-positive glands was not significantly higher than that of p53-negative glands, although there was a trend for higher weight of p53positive adenomas and nodular hyperplastic glands. Likewise, serum PTH levels tended to be higher in p53positive adenomas and nodular hyperplastic glands than in p53-negative tissues. Serum ionized calcium levels were significantly higher in nodular hyperplastic glands, which expressed p53, and the same trend was followed by the other histopathological groups. A previous study also found a positive correlation between preoperative serum calcium and nuclear p53 immunoreactivity, but not serum intact PTH levels (12).

p53 immunostaining does not appear to be useful for differentiating between hyperplasias, adenomas and carcinomas. In fact, most of the carcinomas in our study did not show p53 immunostaining. The only positive one was a metastatic disease. Our series of carcinomas is too small to conclude that p53 is of prognostic value. However, Vargas et al. (14) analyzed 11 parathyroid carcinomas and only observed $\mathrm{p} 53$ protein expression in those with distant metastases. It is possible that, in carcinomas, p53 abnormalities are markers of more aggressive malignancy as with other types of malignant tumors (10). Another possibility is that some carcinomas may have lost genomic sequences through loss of heterozygosity (11). In those cases, p53 would not be detected by immunohistochemistry.

In summary, a high prevalence of p53 immunoexpression was found in secondary parathyroid hyperplasia, showing that expression of $\mathrm{p} 53$ protein is not exclusive to neoplasias in the parathyroid gland. A tendency for higher serum calcium levels was found in patients with parathyroid glands with positive p53 immunoreactivity. Increased p53 expression in parathyroid hyperplastic tissues, if wild-type, could be due to a normal response of the cell to abnormal growth stimulation. p53 modulation may be an important regulating factor in parathyroid tissues subjected to abnormal growth stimulation.

\section{Acknowledgements}

This work was supported by a grant from the Research Support Foundation of the State of São Paulo (FAPESP). $\mathrm{MJK}$ is also supported by FAPESP.

\section{References}

1 Arnold A, Staunton CE, Kim HG, Gaz RD \& Kronenberg HM. Monoclonality and abnormal parathyroid hormone genes in parathyroid adenomas. New England Journal of Medicine 1988318 658-662.

2 Arnold A \& Kim HG. Clonal loss of one chromosome 11 in a parathyroid adenoma. Journal of Clinical Endocrinology and Metabolism 198969 496-499.

3 Friedman E, Bale AE, Marx SJ, Norton JA, Arnold A, Tu T et al. Genetic abnormalities in sporadic adenomas. Journal of Clinical Endocrinology and Metabolism 198971 293-297.

4 Thakker RV, Bouloux P, Wooding C, Chotai K, Broad PM \& Spurr NK. Association of parathyroid tumors in multiple endocrine neoplasia type 1 with loss of alleles on chromosome 11. New England Journal of Medicine 1989321 218-224.

5 Hsi ED, Zukerberg LR, Yang WI \& Arnold A. Cyclin D1/PRAD1 expression in parathyroid adenomas: an immunohistochemical study. Journal of Clinical Endocrinology and Metabolism 199681 1736-1739.

6 Cryns V, Thor A, Xu H, Hu SX, Wierman ME, Vickery AL Jr et al. Loss of the retinoblastoma tumor-suppressor gene in parathyroid carcinoma. New England Journal of Medicine 1994330 757-761.

7 Subramanian P, Wilkinson S \& Shepherd JJ. Inactivation of retinoblastoma gene in malignant parathyroid growths: a candidate genetic trigger? Australian and New Zealand Journal of Surgery $199565714-716$.

8 Chen PL, Chen YM, Bookstein R \& Lee WH. Genetic mechanisms of tumour suppression by the human p53 gene. Science 1990250 1576-1580

9 Velculescu VE \& El-Deiry WS. Biological and clinical importance of the p53 tumor suppressor gene. Clinical Chemistry 199642 858-868.

10 Harris CC \& Hollstein M. Clinical implications of the p53 tumorsuppressor gene. New England Journal of Medicine 1993329 $1318-1327$.

11 Cryns VL, Rubio MP, Thor AD, Louis DN \& Arnold A. p53 abnormalities in human parathyroid carcinoma. Journal of Clinical Endocrinology and Metabolism 199478 1320-1324.

12 Subramaniam P, Wilkinson S \& Shepherd JJ. p53 tumor suppressor gene expression in hyperparathyroidism. Australian and New Zealand Journal of Surgery $199666302-304$. 
13 Wang W, Johansson H, Kvasnicka T, Farnebo L-O \& Grimelius L. Detection of apoptotic cells and expression of Ki-67 antigen, Bcl-2, p53 oncoproteins in human parathyroid adenoma. APMIS 1996 $104789-796$.

14 Vargas MP, Vargas HI, Kleiner DE \& Merino MJ. The role of prognostic markers (MIB-1, RB, and bcl-2) in the diagnosis of parathyroid tumors. Modern Pathology 199710 12-17.

15 Hakim JP \& Levine MA. Absence of p53 point mutations in parathyroid adenoma and carcinoma. Journal of Clinical Endocrinology and Metabolism 199478 103-106.

16 DeLellis RA. Atlas Of Tumor Pathology: Tumors of The Parathyroid Gland, third series. Washington DC: Armed Forces Institute of Pathology, 1991.

17 Grimelius L \& Bondenson L. Histological diagnosis of parathyroid diseases. Pathology Research and Practice 1995191 353-365.

18 Falcheti A, Bale AE, Amorosi A, Bordi C, Cicchi P \& Bandini S. Progression of uremic hyperparathyroidism involves allelic loss of chromosome 11. Journal of Clinical Endocrinology and Metabolism 199376 139-144.

19 Vieira JGH, Nishida SK, Kasamatsu, Amarante EC \& Kunii IS. Development and clinical application of an immunofluorometric assay for intact parathyroid hormone. Brazilian Journal of Medical and Biological Research 199427 2379-2382.

20 Hsu SM, Raine L \& Fanger H. Use of avidin-biotin-peroxidase complex $(\mathrm{ABC})$ in immunoperoxidase technique: a comparison between $\mathrm{ABC}$ and unlabelled antibody (PAP) procedures. Journal of Histochemistry and Cytochemistry 198129 577-580.

21 Barnes DM, Hanby AM, Gillett CE, Mohammed S, Hodgson S, Bobrow LG, Leigh IM, Purkis T, MacGeogh C \& Spurr NK. Abnormal expression of wild type p53 protein in normal cells of a cancer family patient. Lancet 1992340 259-263.

22 Lehman TA, Bennet WP, Metcalf RA, Welsh JA, Ecker J, Modali RV, Ulrich S, Romano JW, Appella E \& Testa JR. p53 mutations, ras mutations, and p53-heat shock 70 protein complexes in human lung carcinoma cell lines. Cancer Research 199151 4090-4096.

23 Momand J, Zambetti GP, Olson DC, George D \& Levine AJ. The mdm-2 oncogene product forms a complex with the p53 protein and inhibits p53-mediated transactivation. Cell $1992691237-$ 1245.

24 Oliner JD, Kinzler KW, Meltzer PS, George DL \& Vogelstein B. Amplification of a gene encoding a p53-associated protein in human sarcomas. Nature 1992358 80-83.

25 Thomas DW. p53 in tumour pathology: can we trust immunocytochemistry? Journal of Pathology 1992166 329-330.

26 Levine AJ. p53, the cellular gatekeeper for growth and division. Cell 199788 323-331.

27 Wang XW \& Harris CC. p53 tumor-suppressor gene: clues to molecular carcinogenesis. Journal of Cellular Physiology 1997173 247-255.

28 Lee Y-S \& Teh M. p53 expression in pseudoepitheliomatous hyperplasia keratoacanthoma, and squamous cell carcinoma of skin. Cancer 199473 2317-2323.

29 Dei Tos AP, Doglioni C, Laurino L, Barbareschi M \& Fletcher CD. p53 protein expression in non-neoplastic lesions and benign and malignant neoplasms of soft tissue. Histopathology 199322 4550 .

30 Wang LD, Hong JY, Qui SL, Gao H \& Yang CS. Accumulation of p53 protein in esophageal precancerous lesions: a possible early biomarker for carcinogenesis. Cancer Research 199353 17831787.

31 Kastan MB, Onyekwere O, Sidransky D, Vogelstein B \& Craig RW. Participation of p53 protein in the cellular response to DNA damage. Cancer Research 199251 6304-6311.

32 Ahomadegbe JC, Barrois M, Fogel S, Le Bihan ML, Dour-Rasy S \& Duvillard P. High incidence of p53 alterations (mutation, deletion, overexpression) in head and neck primary tumors and metastases: absence of correlation with clinical outcome. Frequent protein overexpression in normal epithelium and in early noninvasive lesions. Oncogene 199510 1217-1227.

Received 24 November 1997

Accepted 2 March 1998 